\title{
Personalized Digital Fitness Coach
}

\author{
Leon Rothkrantz \\ Delft University of Technology \\ Delft, The Netherlands \\ Czech Technical University \\ Prague, Czech Republic \\ LJM.Rothkrantz@gmail.com
}

\begin{abstract}
The Corona crisis limits the mobility of people and it proves that many people have an increased body mass index. A lot of people want to increase their fitness and to boost their immune system. There is a run-on fitness schools and fitness equipment for the home environment. At fitness schools, fitness coaches are available for personalized instructions and supervision. Fitness in the home environment lacks personalized instruction and supervision and can cause serious injuries. In this paper a digital coach will be introduced providing digital support and supervision. The digital coach offers personalized fitness program, supervises athletes during fitness exercises and provides a supporting system concerning injuries. A prototype of the developed system can be downloaded as an app on a smart phone.
\end{abstract}

\section{CCS CONCEPTS}

- Computing methodologies $\rightarrow$ Modeling and simulation.

\section{KEYWORDS}

Digital fitness coach, Personalized system, Expert system, CLIPS, Human expert knowledge

\section{ACM Reference Format:}

Leon Rothkrantz. 2021. Personalized Digital Fitness Coach. In International Conference on Computer Systems and Technologies '21 (CompSysTech '21), June 18-19, 2021, Ruse, Bulgaria. ACM, New York, NY, USA, 5 pages. https: //doi.org/10.1145/3472410.3472412

\section{INTRODUCTION}

The Corona crisis caused a run-on fitness schools. Increased fitness and loss of weight stimulates the immune system. But the exponential increase of inflammation rates of the Corona virus necessitated many countries to go lock down. To limit interpersonal contacts many public domains as restaurants, pubs, shopping mall, schools including fitness schools had to close their doors. People were advised to stay at home. TV broadcast with gymnastic exercises became very popular. There was also a run-on fitness equipment ordered via digital shops. Most fitness equipment enables athletes to record some sensor data such as heart rate, blood pressure and respiratory rates during training. But most fitness

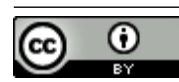

This work is licensed under a Creative Commons Attribution International 4.0 License.

CompSysTech '21, June 18-19, 2021, Ruse, Bulgaria

(C) 2021 Copyright held by the owner/author(s)

ACM ISBN 978-1-4503-8982-2/21/06.

https://doi.org/10.1145/3472410.3472412 equipment lacks a manual or feedback system to interpret recorded data. Some websites provide instructions for beginners. But there is a need for personalized feedback by expert coaches, especially a need for consultancy in case of injuries.

The design of a digital fitness coach has a long history at TUDelft and started around 2000. In 2002 TUDelft student G. J. Eggenkamp was the winner of the famous Boat Race Oxford-Cambridge. He participated three times in the Olympic Games and was winner of a silver medal. He decided together with colleagues to design a digital fitness coach [6]. The expert system was based on his rowing experience. For many years he was coached by experienced training experts affiliated with the rowing club Protheus. He noticed the training advices, exercises and nutrition advices over the years in his logbook. Every week he had to do a fitness test at a digital rowing device and the progress was captured in sensor data. In fact, his logbook was the start of a database of the rowing advices of the coaches affiliated with the rowing club. Data of the fitness room were added to the database. On a weekly basis the results of training were discussed with the coaches and adapted training scheme were added in the database. The database was discussed with all the coaches and for many years the database was the basis for training beginning and advanced athletes. Another computer science student at TUDelft J.Cabbolet designed a digital fitness coach as part of his thesis work [2]. He implemented the ideas and advices of a famous Dutch fitness coach W. Jonkman.

The expert systems of both computer science students defined a unique database to define a digital fitness coach. The problem of current digital fitness systems is that the systems give general guidelines for a fitness training scheme but lack the expertise to advice and comment athletes on the basis of their regular training exercises. After some successful years both systems were only used at the Sport centers of Delft University of Technology. Both systems made a revival at the start of the Corona crisis and an improved version of a personalized fitness coach has been developed.

Most fitness equipment has built in sensors to measure physiological processes during fitness exercises. Some of them are built in handles or belts around the chest. The frequencies and especially the changes in frequencies can be measured. Sensor data recorded during fitness exercises is domain and user specific. The recorded data is quite different from data recorded during daily life. For that reason, the interpretation of the recorded data is left to an expert. Delft University of Technology has a huge fitness center with professional coaches. They also support sport clubs of student's societies. The availability of sport coaches willing to cooperate in the current project guarantees expertise of training and coaching. Our goal is to extract the knowledge from the experts and built in 
an expert system. Another option is to use sensors in smart watches. The knowledge is extracted from experts by interviews.

A second expertise domain is the knowledge of injuries. Experienced fitness instructors are aware of common injuries, especially experienced by starting athletes. A special method of knowledge extraction has been used in this experiment. Experience fitness instructors from the fitness school from Delft University of Technology and gyms in the city of Delft were requested to take the most common injuries met by athletes in their mind. They were also requested to describe the injuries in a few lines, with complaints, causalities and remedies. To validate the knowledge of the coaches, these descriptions were distributed under other instructors and they were requested to diagnose the injuries and to describe remedies against that injury. This resulted in a list of 25 most common injuries with high agreement of the coaches. The knowledge of injuries was built in in an expert system. Athletes can select symptoms from a list and localize the injury in a picture of the body and get remedies as stated by the coaches.

The goal of our research was to develop a fitness app on a smart phone for individual (home) athlete. The system provides advices about starting exercises, analyses the performance and supervises the athlete by cardiac monitoring and breathing monitoring. The system generates personalized feedback and motivates the athlete to complete his exercises. The innovative aspect of our project is that knowledge of experts is used with expert domain knowledge and of fitness (training) programs. Also experienced experts with a computer science background were involved in the project. In this way the focus is more on the content of the fitness app, than on design and implementation. The outline of the paper is as follows. In the next section related work will be presented. Then we present the used sensors and knowledge model of our system. One part of our system is presented in more detail, the support for the rowing equipment. The knowledge base with knowledge from experts is presented in Section 5, 6, with some examples of knowledge rules. Finally, we present the module injuries and in the last section experiences of users.

\section{RELATED WORK}

Zhou et al. (2018) [12] developed a fitness app called CalFit. The innovative aspect of this app was that it enables athletes to set their own dynamic goals and was able to monitor the behavior. The system used reinforcement learning and defines new but attainable behavior. The system was developed at the University of California and tested on a group of 20 students from that University. The first results were promising but a bigger group of test persons was needed. The development team should be enlarged with personal fitness trainers to set up innovative programs.

A personalized fitness coach is for many people not realizable or not available all the time. An alternative is to create a smart coach using Digital Twin technology. It combines machine learning and human-computer interaction and is related to the development of innovative AI algorithms implemented on smart phones and smart watches. Díaz et al. (2000) [5] provides a survey of digital twin coaching for physical activities. The focus is on used machine learning technology used in Digital Twin Coaching. They present all possible sensors used in developed systems varying from accelerometer/gyroscope, Electroencephalogram (EEG) and Electromyography (EMG) sensors, RGB Camera/RGB-D Camera, infrared Camera, Kinect, dynamometer, Heart Rate (HR) monitor and oxygen monitor. Also, relevant algorithms from Artificial Intelligence are reviewed. The authors expect that in next future researchers will focus on security and privacy aspects and creation and analysis of huge databases.

Kranz et al. (2013) [7] present a smart phone system. Using the sensors in the smart phone, the system is able to give support to users, ranging from data logging, automated activity recognition and providing feedback. Principal Component Analysis was used to analyze recorded data and to provide feedback. In their paper the authors tested 15 available fitness apps on the availability of GPS trackers for outdoor activities, workout planners and exercise books. Based on the outcomes of the test, the authors define some guidelines for the design of fitness apps with respect to usability, instructional quality, and long-term motivation. The developed fitness app was tested using balanced board training. Next future the authors plan more exercise types and the integration of the system in health platforms. A recent app was developed in by Middelweerd et al (2014) [8].

Schneider (2017) [11] states that users of digital fitness coaches abandon these technologies quickly because provided feedback is not personalized or adapted to the situation or consists of difficult to implement statistics. It proves that most athletes show a slow progress or even decline in performance. Providing feedback makes sense at regular times. Feedback about injuries should be provided immediately. The authors investigated the possibility to design personalized and adaptive fitness coaches. The first available prototypes were investigated by Schmidt et al. (2015) [10].

\section{SENSORS}

Current fitness equipment has built in sensors to measure heartrate, breathing frequency, and energy consumption. Most students also have smart watches, smart phones with built in sensors such as accelerometer and gyroscope. The two devices smart phone and smart watch can be connected using Bluetooth. The accelerometer was used for behavior recognition, such as detection of walking, running or falling. In Figure 1 and 2 we show some examples of recorded data by accelerometer on Android phone.

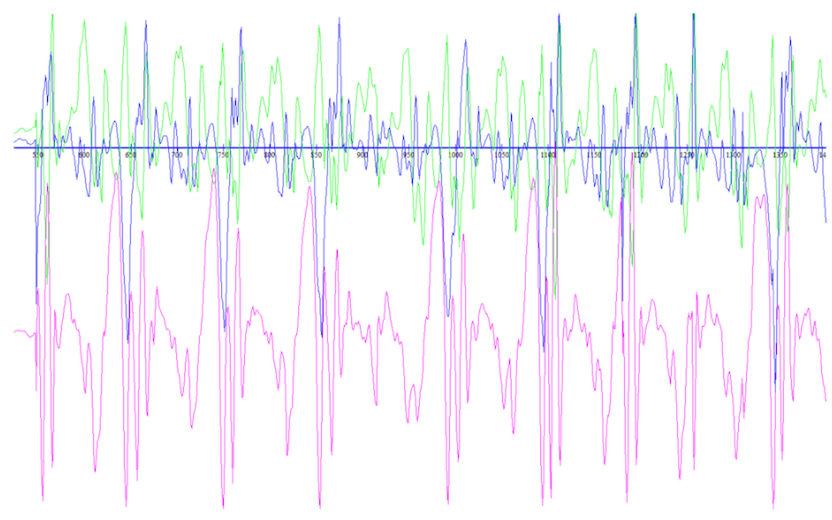

Figure 1: Accelerator signals during walking. 


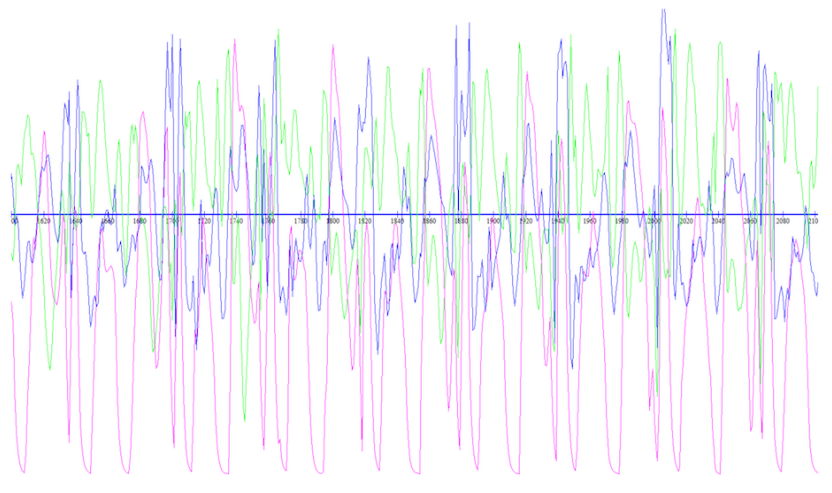

Figure 2: Accelerator signals during running.

More advanced sensor measurement of blood pressure using video plethysmography by smart cameras is presented in [3]. In the same paper automatic heart rate analysis was performed in a contactless way using smart cameras. The analysis was based on the Active Appearance model which is commonly used in facial analysis research. In a comparison analysis it proves that heart analysis via a smart watch is easier to perform than analysis via a smart camera. At this moment heart rate analysis is done via the camera attached to a smart phone. The use of smart camera or smart watch enables personalized use. In [4] and [9], we developed surveillance systems using a network of smart sensors. The goal was to research the usability and performance of different sensors.

\section{KNOWLEDGE MODEL}

The fitness app is supposed to provide support and monitoring athletes during their fitness exercise. During design of the fitness app the following assumptions were made:

Athlete Goals. An athlete may have different goals to start fitness exercises such as creating muscle mass, losing weight, aerobics, all round or sport specific. In the list of exercises is an indication of the goals. But for the moment the focus is on general fitness.

Training schedule. It would be nice to have a system which is able to recognize exercises of an athlete in action. At this moment a limited set of behaviors can be assessed by the sensors. From the other site it is good if an athlete is able to make his planning and set his goals in advance. The system will check for inconsistencies, missing elements and not realizable goals. An exercise should always start with a warming up and end with a cool-down. Especially starting athletes start with non-realistic goals.

Monitoring. The used fitness equipment has a limited set of sensors for monitoring, a sensor to measure heart beat and a sensor for the breath rhythm. Fitness coaches have the knowledge about the range of the used sensor measurements. An alarming function is implemented for sharp peaks. An alarming message will be generated. In case the measurements are below the expected level the athlete gets a message that on average the tempo is higher. It proves that the sensor measurement can vary a lot for individual athlete. The system is based on the measurements of a cohort of athletes.
History. After every session the system presents an overview of the performance. Performances of past exercises are summarized in tables. It is possible to read progress from the tables.

Database. Students take part in fitness activities for many years and the performances are recorded in a database in an anonymous way. The data in the database is analyzed by the involved researchers and implemented in the current version of the app.

\section{INJURIES}

In Table 1 and Table 2, we provide an overview of location of injuries and related symptoms. The next challenge is to find specific injuries on the basis of reported symptoms and location of injuries, or to request for more data. In the rest of the chapter, we present our used methodology of knowledge extraction.

Table 1: Overview locations of injuries and related symptoms

\begin{tabular}{ll}
\hline Symptom & Location \\
\hline Pain in muscle(s) during workout & Neck \\
Pain in muscles(s) after workout & Shoulders \\
Pain disappears during warming up & Left and right elbow \\
Pain disappears during light ver- & Left and right wrist \\
sion workout & \\
Swollen tissue & Fingers \\
Red color tissue & Left and right upper arm \\
Numbness or tingles in arms and & Region around spinal \\
fingers & \\
Stiffness of muscles & Thighs \\
Inability to move arms or legs & Knees \\
Inability to move or rotate head & Calves \\
Abnormal position limbs & Ankles \\
Icepacks or rest provide relief of the & Heel \\
pain & \\
Light massage reliefs pain & Toes \\
\hline
\end{tabular}

The "injury" module has been developed as a rule-based system, inspired by the famous MYCIN medical expert system [1]. In 1984 a team of medical doctors affiliated with Stanford University developed a rule-based system to diagnose diseases on the bases of symptoms by patients. To develop the expert system a list of diseases and related symptoms were developed. To develop the relations between characteristic symptoms and diseases the team of medical experts played games. A doctor played the role of patient and took a disease in his mind. Other doctors in the team have to make diagnoses by asking questions about symptoms. In this way the medical team discovered the rules-based relations between symptoms and diseases.

To develop the injury module the designers used a similar methodology as the MYCIN designers. By reviewing experienced fitness coaches associated with TUDelft, it proves that there are a limited number of dominant injuries. To extract the knowledge about injuries from experts, the following procedure was used. In total 12 coaches from the fitness center and sport clubs from the student society, took part in the research. They were requested to take 5 most 
Table 2: List of some common injuries during fitness training

\begin{tabular}{|c|c|c|c|}
\hline Injury & Causal & Symptoms & Treatment \\
\hline $\begin{array}{l}\text { Carpal tunnel } \\
\text { syndrome }\end{array}$ & $\begin{array}{l}\text { In the wrist there is a tunnel } \\
\text { for the median nerve. In this } \\
\text { syndrome the nerve is under } \\
\text { pressure. }\end{array}$ & $\begin{array}{l}\text { Swollen painful tissue in wrist } \\
\text { area, red inflammation color, } \\
\text { numbness, tingles in arms and } \\
\text { fingers. }\end{array}$ & $\begin{array}{l}\text { Avoid repeated hand and wrist movements, use } \\
\text { correct posture, and shake hands to release pres- } \\
\text { sure.Consult medical expert. }\end{array}$ \\
\hline $\begin{array}{l}\text { Low back- } \\
\text { pain }\end{array}$ & $\begin{array}{l}\text { This injury is caused by } \\
\text { heavy weights power lifting. }\end{array}$ & $\begin{array}{l}\text { Wrong posture during lifting, as } \\
\text { rounding the back. Annoying } \\
\text { pain in the back region, troubles } \\
\text { in moving muscles of the legs. }\end{array}$ & $\begin{array}{l}\text { Special power-lift exercises, twisting motions, post- } \\
\text { pone squats exercises for one week. }\end{array}$ \\
\hline $\begin{array}{l}\text { Straining } \\
\text { muscle }\end{array}$ & $\begin{array}{l}\text { Overstretching a muscle } \\
\text { during heavy lifting, row- } \\
\text { ing, jumping, or running at } \\
\text { high speed. }\end{array}$ & $\begin{array}{l}\text { Swelling and weakness of mus- } \\
\text { cles or related tendons, painful } \\
\text { muscle. }\end{array}$ & $\begin{array}{l}\text { Keep muscle in relaxed position, use ice packs, start } \\
\text { training session with warming up, stretching exer- } \\
\text { cises, consult medical expert for anti-inflammatory } \\
\text { medication. }\end{array}$ \\
\hline Tennis elbow & $\begin{array}{l}\text { Heavy, repeated weight lift- } \\
\text { ing using stretched arm. }\end{array}$ & $\begin{array}{l}\text { Sharp pain in elbow starting } \\
\text { training session. }\end{array}$ & $\begin{array}{l}\text { Start training session with low weights, increase } \\
\text { weights, keeping wrist in neutral position, start with } \\
\text { minimal number of training sets, don't wiggle elbows } \\
\text { during exercise, and use dumbbells. }\end{array}$ \\
\hline $\begin{array}{l}\text { Muscle } \\
\text { spasm, mus- } \\
\text { cle cramps }\end{array}$ & $\begin{array}{l}\text { Overuse, dehydration of a } \\
\text { muscle, not properly, inad- } \\
\text { equate warming up. }\end{array}$ & $\begin{array}{l}\text { Painful muscle cramps, involun- } \\
\text { tary contraction of muscles, in- } \\
\text { ability to use a specific muscle, } \\
\text { muscle spasm. }\end{array}$ & $\begin{array}{l}\text { Drinking a lot of water before the training and during } \\
\text { training, during cramp gently stretching the muscle. } \\
\text { Rest, professional massage, keep hydrated during } \\
\text { training session, use a warming up sessions before } \\
\text { training. }\end{array}$ \\
\hline
\end{tabular}

frequent injuries during fitness in their mind, which are the most important or frequent injuries. They describe the injuries, mentioning the symptoms, exercises and treatments. On a meeting the coaches played the following game. Alternately a coach presents an injury by showing the location of the symptoms and corresponding exercise. The other coaches were requested to guess about the injuries and treatments. It was possible to select 15 injuries with a high agreement between the expert coaches. The extracted knowledge was converted to "if-then" rules and implemented in our knowledge base system.

\section{ROWING MODULE}

Delft University of Technology has a long tradition in rowing by students. The presence of rivers, channels and lakes stimulates water activities. In total of 5 student societies have their own boats, fitness center and coaches. They attract every year hundreds of students visiting the club for training. A minority practices every day for many hours as preparation for National and International contests, including the Olympic Games. Over the years the coaches have developed successful training programs, including general fitness program. Many students especially students living in student houses, have their own in-house training facilities, including fitness equipment. Students used written instructions and training schemas to do their daily/weekly exercises. For two years, the fitness app is introduced and downloaded and tested by many students. Especially the fact that Olympic rowers and their coaches designed and implemented fitness modules attracted many students [6]. But starting athletes have a lot of enthusiasm, but miss knowledge of physiology and training and many of them get over trained after start.
The rowing module has been developed using an incremental model. Successive "increments" have been developed, verified and validated. The available knowledge in written and documented material was converted to knowledge rules (if-then) and implemented using CLIPS-code with user interface (Delphi). It starts with the salience (priority) of the rule. The rule with the highest salience on the agenda of the expert system is allowed to fire. Next in a description, the function of the knowledge rule will be explained and which facts on the bulletin board are needed. Much more details can be found in [6].

\section{EVALUATION}

In total 240 students from TUDelft downloaded the fitness app. In total 35 students were random selected and requested to come to the fitness center of TUDelft with their personalized fitness to do their exercises at the center under supervision of a fitness coach. The coaches observed the performance of students and asked some open question about the user satisfaction with the app. They made the following observations.

(1) Starting students were motivated to use the fitness app and had the most benefit from it. More experienced students need more advanced and specialized advises.

(2) In the planning some students forgot the warming up and cool down.

(3) Some starting students were dissatisfied about their fitness progress and had the feeling that the digital coach slopes down the training process and stimulated an average training schema. 
(4) Students were satisfied about the injury module especially that they could consult the digital coach in an anonymous way, anytime, anywhere.

(5) Students were complaining about the fact that they received many times similar comment. It proved to be difficult to give personalized comment in daily use of the app.

(6) The physiological condition of students may change, caused by external reasons. This is not included in the app.

\section{CONCLUSION}

Thanks to Corona, fitness centers at Universities and in the city were closed. Students were invited to create their fitness center in their home environment. It was also the wish of some computer science students, sporting at an advanced level to offer their expertise to peer students. This resulted in a first release of a fitness app distributed under students. The rowing module and injury module were highly appreciated because the implemented expertise of experts was evident. Feedback after a short period of training was most adequate. Comment over a longer period was difficult because of small progress of athletes and lack of sensitivity of used sensors. Most available digital fitness coaches provide only general, not personalized and adaptive feedback. The current system is based on the long year experience of the designers as top athletes and the shared knowledge base of coaches involved in supervising athletes.

A rule-based system works optimal in case of detection of failures and recommendations. The current system is based on the wellknown medical expert system MYCIN. Lack of motivation and losing interest are difficult to detect by the used sensors. Next future audio-visual equipment [4] will be used to detect special facial expressions, body movements and utterances to measure the intensity of the performance.

\section{REFERENCES}

[1] Bruce G. Buchanan and Edward H. Shortliffe. 1984. Rule Based Expert Systems: The Mycin Experiments of the Stanford Heuristic Programming Project (The AddisonWesley Series in Artificial Intelligence). Addison-Wesley Longman Publishing Co.
Inc., USA.

[2] Jeroen Cabbolet. 2000. Willem's knowledge expert system: a total gym solution, Thesis. Master's thesis. Delft University of Technology.

[3] Dragos Datcu, Marina Cidota, Stephan Lukosch, and Léon Rothkrantz. 2013. Noncontact Automatic Heart Rate Analysis in Visible Spectrum by Specific Face Regions. In Proceedings of the 14th International Conference on Computer Systems and Technologies (CompSysTech '13). Association for Computing Machinery, New York, NY, USA, 120-127. https://doi.org/10.1145/2516775.2516805

[4] Dragoş Datcu and Léon Rothkrantz. 2007. Facial Expression Recognition in Still Pictures and Videos Using Active Appearance Models: A Comparison Approach. In Proceedings of the 2007 International Conference on Computer Systems and Technologies (CompSysTech '07). Association for Computing Machinery, New York, NY, USA, Article 112, 6 pages. https://doi.org/10.1145/1330598.1330717

[5] Rogelio Gámez Díaz, Qingtian Yu, Yezhe Ding, Fedwa Laamarti, and Abdulmotaleb El Saddik. 2020. Digital Twin Coaching for Physical Activities: A Survey. Sensors 20, 20 (2020), 1-21. https://doi.org/10.3390/s20205936

[6] Gerritjan Eggenkamp and Joost Fleuren. 1999. Rowing Expert, Technical Report, Delft University of Technology.

[7] Matthias Kranz, Andreas Möller, Nils Hammerla, Stefan Diewald, Thomas Plötz, Patrick Olivier, and Luis Roalter. 2013. The mobile fitness coach: Towards individualized skill assessment using personalized mobile devices. Pervasive and Mobile Computing 9, 2 (2013), 203-215. https://doi.org/10.1016/j.pmcj.2012.06.002 Special Section: Mobile Interactions with the Real World.

[8] Anouk Middelweerd, Julia S. Mollee, C. Natalie van der Wal, Johannes Brug, and Saskia J. te Velde. 2014. Apps to promote physical activity among adults: a review and content analysis. International fournal of Behavioral Nutrition and Physical Activity 11, 1 (2014), 97. https://doi.org/10.1186/s12966-014-0097-9

[9] Léon J. M. Rothkrantz. [n.d.]. Smart surveillance systems. In Biometrics: Concepts, Methodologies, Tools, and Applications, Information Resources Management Association (Ed.). Hershey, PA: IGI Global, 1619-1642. https://doi.org/10.4018/978-15225-0983-7.ch068

[10] Benedikt Schmidt, Sebastian Benchea, Rüdiger Eichin, and Christian Meurisch. 2015. Fitness Tracker or Digital Personal Coach: How to Personalize Training. In Adjunct Proceedings of the 2015 ACM International foint Conference on Pervasive and Ubiquitous Computing and Proceedings of the 2015 ACM International Symposium on Wearable Computers (UbiComp/ISWC'15 Adjunct). Association for Computing Machinery, New York, NY, USA, 1063-1067. https: //doi.org/10.1145/2800835.2800961

[11] Hanna Schneider. 2017. Adapting at Run-Time: Exploring the Design Space of Personalized Fitness Coaches. In Proceedings of the 22nd International Conference on Intelligent User Interfaces Companion (IUI '17 Companion). Association for Computing Machinery, New York, NY, USA, 173-176. https://doi.org/10.1145/ 3030024.3038280

[12] Mo Zhou, Yonatan Mintz, Soshimi Fukuoka, Ken Goldberg, Elena Flowers, Philip Kaminsky, Alejandro Castillejo, and Anil Aswani. 2018. Personalizing Mobile Fitness Apps using Reinforcement Learning. In Proceedings of CEUR Workshop, http://ceur-ws.org, Vol 2068. 